University of Nebraska - Lincoln

DigitalCommons@University of Nebraska - Lincoln

2013

\title{
A comprehensive change detection method for updating the National Land Cover Database to circa 2011
}

Suming Jin

U.S. Geological Survey, sjin@usgs.gov

Limin Yang

U.S. Geological Survey

Patrick Danielson

U.S. Geological Survey

Collin Homer

U. S. Geological Survey

Joyce Fry

U.S. Geological Survey

See next page for additional authors

Follow this and additional works at: https://digitalcommons.unl.edu/usgsstaffpub

Jin, Suming; Yang, Limin; Danielson, Patrick; Homer, Collin; Fry, Joyce; and Xian, George, "A comprehensive change detection method for updating the National Land Cover Database to circa 2011" (2013). USGS Staff -- Published Research. 711.

https://digitalcommons.unl.edu/usgsstaffpub/711

This Article is brought to you for free and open access by the US Geological Survey at DigitalCommons@University of Nebraska - Lincoln. It has been accepted for inclusion in USGS Staff -- Published Research by an authorized administrator of DigitalCommons@University of Nebraska - Lincoln. 


\section{Authors}

Suming Jin, Limin Yang, Patrick Danielson, Collin Homer, Joyce Fry, and George Xian 


\title{
A comprehensive change detection method for updating the National Land Cover Database to circa 2011
}

\author{
Suming Jin ${ }^{\mathrm{a}, *, 1}$, Limin Yang ${ }^{\mathrm{b}}$, Patrick Danielson ${ }^{\mathrm{c}, 2}$, Collin Homer ${ }^{\mathrm{d}}$, Joyce Fry ${ }^{\mathrm{d}}$, George Xian ${ }^{\mathrm{a}, 1}$

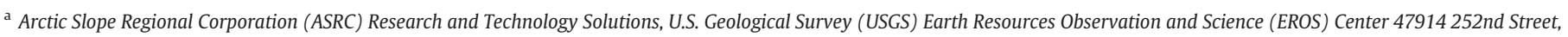 \\ Sioux Falls, SD 57198, United States

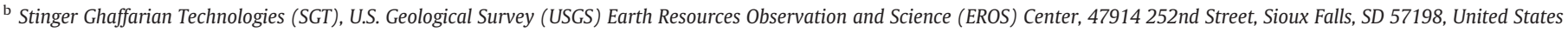 \\ c Stinger Ghaffarian Technologies (SGT), Contractor to the U.S. Geological Survey (USGS) Earth Resources Observation and Science (EROS) Center, 47914 252nd Street, Sioux Falls, \\ SD 57198, United States \\ ${ }^{\mathrm{d}}$ U.S. Geological Survey (USGS) Earth Resources Observation and Science (EROS) Center 47914 252nd Street, Sioux Falls, SD 57198, United States
}

\section{A R T I C L E I N F O}

\section{Article history:}

Received 20 July 2012

Received in revised form 15 January 2013

Accepted 16 January 2013

Available online $\mathrm{xxxx}$

\section{Keywords:}

National Land Cover Database 2011

Change detection

\begin{abstract}
A B S T R A C T
The importance of characterizing, quantifying, and monitoring land cover, land use, and their changes has been widely recognized by global and environmental change studies. Since the early 1990s, three U.S. National Land Cover Database (NLCD) products (circa 1992, 2001, and 2006) have been released as free downloads for users. The NLCD 2006 also provides land cover change products between 2001 and 2006. To continue providing updated national land cover and change datasets, a new initiative in developing NLCD 2011 is currently underway. We present a new Comprehensive Change Detection Method (CCDM) designed as a key component for the development of NLCD 2011 and the research results from two exemplar studies. The CCDM integrates spectral-based change detection algorithms including a Multi-Index Integrated Change Analysis (MIICA) model and a novel change model called Zone, which extracts change information from two Landsat image pairs. The MIICA model is the core module of the change detection strategy and uses four spectral indices (CV, RCVMAX, dNBR, and dNDVI) to obtain the changes that occurred between two image dates. The CCDM also includes a knowledge-based system, which uses critical information on historical and current land cover conditions and trends and the likelihood of land cover change, to combine the changes from MIICA and Zone. For NLCD 2011, the improved and enhanced change products obtained from the CCDM provide critical information on location, magnitude, and direction of potential change areas and serve as a basis for further characterizing land cover changes for the nation. An accuracy assessment from the two study areas show $100 \%$ agreement between CCDM mapped no-change class with reference dataset, and $18 \%$ and $82 \%$ disagreement for the change class for WRS path/row p22r39 and p33r33, respectively. The strength of the CCDM is that the method is simple, easy to operate, widely applicable, and capable of capturing a variety of natural and anthropogenic disturbances potentially associated with land cover changes on different landscapes.
\end{abstract}

(c) 2013 Elsevier Inc. All rights reserved.

\section{Introduction}

Global and regional assessments on land cover and land use status and changes are fundamentally important for climate and environmental change studies (Foley et al., 2005; Matthews et al., 2004; Turner et al., 2007). While some changes in land cover, such as long-term changes, are due to natural causes, human activity increasingly plays an important role in changing the land cover and land use throughout the world. The importance of characterizing, quantifying, and monitoring these changes through remotely sensed and geospatial data as a key component of the land change science has been widely recognized by global and environmental change studies (Turner et al., 2007).

\footnotetext{
* Corresponding author. Tel.: +1 6055942912.

E-mail address: sjin@usgs.gov (S. Jin).

1 Work performed under USGS contract G08PC91508.

2 Work performed under USGS contract G10PC00044.
}

Digital change detection is a process of determining and quantifying changes based on co-registered, multitemporal remotely sensed data (e.g., Green et al., 1994; Loveland et al., 2002; Yang \& Lo, 2002; Yang et al., 2003). Many remote sensing change-detection methods have been developed (e.g., Hansen et al., 2008; Healey et al., 2005; Huang et al., 2010; Jensen et al., 1995; Jin \& Sader, 2005; Kam, 1995; Kennedy et al., 2009; Latifovic \& Pouliot, 2005; Lunetta et al., 2006; Ridd \& Liu, 1998; Sader \& Winne, 1992; Sohl, 1999) and reviewed since the late 1980s (e.g., Gong et al., 2008; Jensen et al., 1995; Kam, 1995; Lu et al., 2004; Ridd \& Liu, 1998; Singh, 1989). In general, two principal approaches are commonly used for change detection: 1) a spectral-based approach by which simultaneous analysis of multitemporal and/or multispectral data is conducted, and 2) a post-classification based approach when independent classifications are made and compared to derive information on changes. A hybrid approach using both 1) and 2) can also be adopted in land cover change study. 
A general consensus among researchers is that there is no single method/algorithm that can be universally applicable for change detection and analyses. This is especially the case when large area and regional scale land cover change detection is involved. The main challenge is how to accurately extract land cover changes while distinguishing them from other non-land cover changes caused by natural variability (e.g., weather and climate conditions) and other extraneous factors. A pressing need is to develop robust, efficient, and accurate automated or semi-automated methods necessary for cost effectively monitoring land cover changes at the regional to global scales. This is an ongoing and challenging research topic primarily because using remote sensing data alone sometimes falls short in detecting land cover changes over large geographic regions due to the "ill-defined" problem (e.g., spectral similarity of different land cover classes) similar to that faced by remote-sensing-based biophysical parameter inversion. Hence, it is reasonably concluded that land cover changes can be better detected and quantified at the global and regional scales if multi-source data that cover the temporal, spectral, and thematic domains are to be integrated, analyzed, and interpreted simultaneously.

With a few exceptions, most of the national and regional land cover change projects detect change by using only one pair of images acquired from a growing season, so they lack information on the persistence of changes within and across a season (Pouliot et al., 2009; Zhan et al., 2000). Recent developments using a trajectory-based change detection method using a high temporal frequency Landsat imagery stack had some success (Huang et al., 2008; Kennedy et al., 2010). The approach is promising but was developed primary for detection of forest changes and disturbances and has not been tested for other land cover types. Another challenge is that change detection based on spectral data alone is often not sufficient to detect many types of land cover changes over a large geographic area. It is often desirable to incorporate prior knowledge about land cover and land cover change trajectory along with detected spectral change to improve detection and analysis of land cover change (Gong et al., 2008; Latifovic and Pouliot, 2005).

One potential promising approach is to detect land cover changes using a strategy that integrates a remote sensing technique with a knowledge-based system. The knowledge-based system embodies expert opinion and rules on certain types of land cover changes. Expert knowledge can be expressed as rules and/or attributes derived and assembled from the spectral, spatial, and temporal domains, and the geospatial knowledge about land cover change and trajectories can be built into the system. Within the system, multiple rules and hypotheses can be linked together that ultimately describe the target land cover change classes (Shafer \& Logan, 1987; Srinivasan \& Richards, 1990).

The primary goal of the research is to develop and evaluate a Comprehensive Change Detection Methodology (CCDM) as a key component for development of a new generation of the National Land Cover Database (NLCD) 2011. The objective of NLCD 2011 is to capture the land cover land use change since previous NLCD 2006 and update the national land cover map. The objective of the CCDM is to detect areas of spectral changes between 2006 and 2011 where either a land cover change or a land disturbance, caused by either a natural or anthropogenic agent, has occurred. The CCDM integrates spectral information from multi-date Landsat images, information on land cover status, and prior knowledge about the trajectory of land cover trends. It is important for the CCDM to minimize the spurious spectral changes caused by variation in vegetation phenology and/or the interannual variability of weather condition, rather than by land cover changes or land disturbances. For NLCD 2011, the product generated by CCDM is regarded as the Maximum Potential Change (MPC) that captures all potential land cover change areas rather than only areas where actual land cover change occurred, that is, only a portion of the MPC is related to actual land cover and land use changes (e.g. land conversion). The final land cover change product of NLCD 2011 is derived by integrating the MPC with the NLCD 2006 and NLCD 2011 land cover classification results. Through this integration, only those pixels within MPC that observed a real land cover change between 2006 and 2011 will be retained in the final land cover change product. Together, the MPC and the final land cover change are the two separate yet complimentary products of the NLCD 2011.

Given the objective of the NLCD 2011, the performance of CCDM is to be measured and evaluated by comparing change area detected by CCDM against the independent data of actual land cover and land use change. The CCDM is a general and robust method designed to be applicable to all the WRS path/rows across the conterminous United States. The CCDM method has been gone through several-stage of test and evaluation, which involved five Landsat path/row during an initial strategy development and eight Landsat path/rows during two operational tests. Those Landsat path/rows cover several ecoregions of the conterminous United States where a variety of natural and anthropogenic induced land cover change and disturbances occurred. In this paper, we describe in detail our comprehensive change method for updating NLCD 2011 with NLCD 2006 as a base, and illustrate the method with two case studies.

\section{Background}

Over the past two decades, one major effort in developing national land cover characterization and land cover change products for the United States was made by the Multi-Resolution Land Characteristics (MRLC) consortium. Through the MRLC (http://www.mrlc.gov/), there have been three major products released to the public named National Land Cover Database (NLCD): a circa NLCD 1992 for the conterminous United States with one thematic layer of land cover (Vogelmann et al., 2001); a circa NLCD 2001 with three thematic layers including land cover, percent imperviousness, and percent tree canopy for all 50 states (Homer et al., 2004, 2007); and a circa NLCD 2006 with three primary products including land cover, percent imperviousness, and land cover change from 2001 to 2006. The NLCD 2006 is the first nationalscale mapping project that assessed land cover change for every pixel of the conterminous United States (Fry et al., 2011) and represents the shift of emphasis from characterizing land cover alone to monitoring the nation's land cover change.

For developing NLCD 2006 and land cover change product, Xian and Homer (2009) proposed a method to update NLCD 2001 to a nominal date of 2006 by using both Landsat imagery and data from NLCD 2001 as the baseline. When the method was developed, free Landsat data were not available. For the cost effective consideration, the method was designed to use only one pair of Landsat scenes in each path and row for change detection. Pairs of Landsat scenes in the same season in 2001 and 2006 were acquired according to WRS paths and rows and normalized to allow calculation of change vectors between the two dates. Conservative thresholds based on Anderson Level I land cover classes were used to segregate the change vectors (CV) and determine areas of change and no-change. This method, while effective in many applications, is based on only one spectral index (i.e., the change vector) and the land cover information from NLCD 2001. Therefore, the method can still yield omission errors because CV is not sensitive to certain types of land cover changes, such as those near the water boundaries and those caused by forest fires on terrain with a certain slope. The result of the method also tends to contain substantial commission errors because of the conservative threshold set for detecting changes for the purpose of reducing omission errors. To correct the commission errors it is often necessary to conduct labor-intensive post-change detection editing.

To improve the NLCD 2006 operational process, we developed a Multi-Index Integrated Change Analysis (MIICA) method at the later stage of the NLCD 2006 project to alleviate commission and omission errors by using four spectral indices that complement each other. In addition to change location, the MIICA also generates change direction information. The operational development of NLCD 2006 showed that the MIICA, compared to $\mathrm{CV}$, can systematically lower both 
commission and omission errors in detecting land cover changes over different regions with a variety of landscapes. Hence, for spectral change detection, the NLCD 2006 adopted the MIICA method as the operational procedure (Fry et al., 2011) considering the major improvements beyond the CV-based approach reported in Xian and Homer (2009).

In early 2011, the MRLC initiated a research and development phase for the production of NLCD 2011. A new strategy for NLCD 2011 change detection has been developed by incorporating lessons learned from the NLCD 2006 production. The new change detection strategy employs spectral-based change detection algorithms to extract change information from multitemporal and multispectral remotely sensed data, including MIICA and another novel change method called Zone. In addition, the new strategy also includes a knowledge-based system that provides critical information on land cover status and trends and the likelihood of land cover change. For each Landsat path and row, implementation of the new strategy uses two image pairs for spectral change analysis in order to reduce commission and omission errors caused by seasonal and phenology changes. It is noted that the output of this new spectral change detection approach is not equivalent to the NLCD 2011 final land cover change product. Instead, it is one of the intermediate products of the NLCD 2011 that provides critical and rich information on location and magnitude of potential change areas and serves as the basis for characterizing land cover changes for the nation.

\section{Methods}

\subsection{Overview of the comprehensive change detection method (CCDM)}

The CCDM (Fig. 1) includes three major components: MIICA (see Section 3.2), Zone (Section 3.3), and Combination (Section 3.4) of change results from two Landsat image pairs. The MIICA is a change detection method that uses four spectral indices to capture a full range of land cover disturbance and land cover change patterns between two dates. Zone is a change detection method that is specifically designed to detect the changes related to forest such as forest regeneration, forest fire, and forest harvest. Zone is a supplementary change detection method for MIICA, especially for regions where frequent forest disturbance happens, because Zone is more sensitive to detecting subtle changes. Both MIICA and Zone will each generate a change map with two change classes: Biomass Increase (BI) and Biomass Decrease (BD). Because MIICA and Zone will be applied to each of the two image pairs, a combination strategy is developed to integrate the change results of the two pairs based on a set of logical rules to reduce commission and omission errors at the same time.

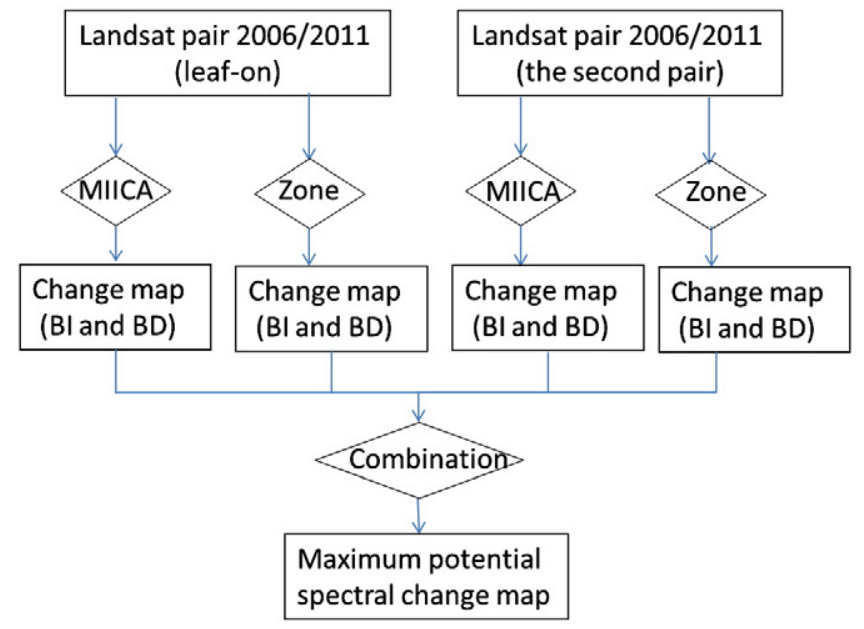

Fig. 1. Flowchart of general change detection strategy in the study.
The CCDM procedures are implemented by mappers for each and every WRS path/row within U.S. in a consistent way.

As indicated in Fig. 1, two image pairs of circa 2006 and circa 2011, ideally one leaf-on pair and one leaf-off pair, are selected for each path/row. All the images are preprocessed following the MRLC 2001 protocol (Chander et al., 2009). Image pairs are geometrically corrected and converted to top-of-atmosphere reflectance. The topof-atmosphere reflectance for all six reflective bands (bands $1-5,7$ ) is multiplied by 400 to rescale the data into unsigned 8-bit range. Clouds and their shadows are masked out for each individual Landsat image.

\subsection{Multi-Index Integrated Change Analysis (MIICA)}

The MIICA (Fig. 2) has been developed to capture a full range of land cover disturbance and potential land cover change patterns, including both change spatial location and change direction (BI and BD). Recognizing the complementary nature of the multiple spectral indices in detecting different land cover changes, we integrated four indices into the MIICA model to more accurately detect true land cover changes between two dates. The four indices are the differenced Normalized Burn Ratio (dNBR), the differenced Normalized Difference Vegetation Index (dNDVI), the Change Vector (CV), and a new index called the Relative Change Vector Maximum (RCVMAX) (Eqs. (1)-(4)).

$\mathrm{dNBR}=\left(\mathrm{B}_{14-} \mathrm{B}_{17}\right) /\left(\mathrm{B}_{14}+\mathrm{B}_{17}\right)_{-}\left(\mathrm{B}_{24-} \mathrm{B}_{27}\right) /\left(\mathrm{B}_{24}+\mathrm{B}_{27}\right)$

$\mathrm{dNDVI}=\left(\mathrm{B}_{14-} \mathrm{B}_{13}\right) /\left(\mathrm{B}_{14}+\mathrm{B}_{13}\right)_{-}\left(\mathrm{B}_{24-} \mathrm{B}_{23}\right) /\left(\mathrm{B}_{24}+\mathrm{B}_{23}\right)$

$\mathrm{CV}=\sum_{i}\left(B_{1 i}-B_{2 i}\right)^{2}$

$\operatorname{RCVMAX}=\sum_{i}\left[\left(B_{1 i}-B_{2 i}\right) / \max \left(B_{1 i}, B_{2 i}\right)^{2}\right]$

where $B_{1 i}(i=1 \ldots 5,7)$ denotes the $i$ th band of the early date Landsat image, $B_{2 i}(i=1 \ldots 5,7)$ means the $i$ th band of the late date Landsat image, and $\max (\mathrm{B} 1 i, \mathrm{~B} 2 i)$ means the maximum value of $\mathrm{B}_{1 i}$ and $\mathrm{B}_{2 i}$.

These four indices complement each other. The $\mathrm{CV}$ captures the absolute value of total spectral change between two dates and likely shows the general change pattern (i.e., higher $\mathrm{CV}$ value reflects larger spectral change which indicates a higher possibility of change in land

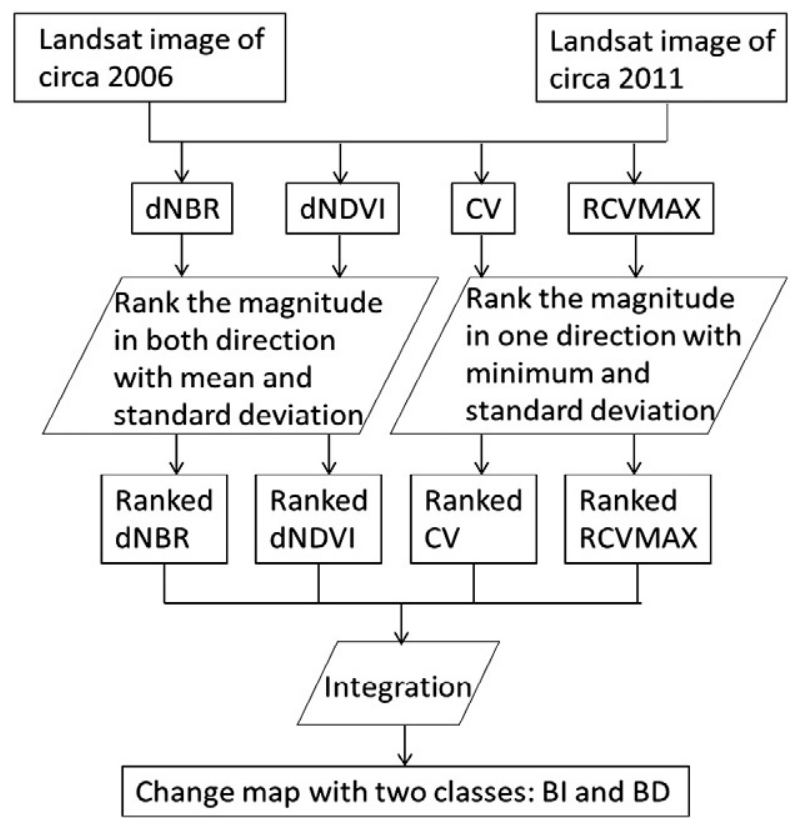

Fig. 2. The flowchart of the MIICA model. 
cover type), yet the magnitude of CV is heavily affected by the land cover and land use types. For example, agriculture lands tend to be highlighted using CV alone due to distinct seasonal and phenology changes and frequent crop rotations even though the land use remains unchanged; in contrast, change of water tends to be difficult to detect by CV because of the low spectral reflectance of water. The RCVMAX measures the relative total spectral change between two dates. RCVMAX can quantify the magnitude of relative change and shows a general change pattern. A greater RCVMAX indicates a higher possibility of change. For example, it can detect changes that occurred at water boundaries very well. However, both RCVMAX and CV can generate some noise (false changes) because of the impacts by terrain, atmosphere, and phenology and may not be optimal for detecting certain types of disturbances; neither will provide information on change direction. Because of the limitation, two other commonly used spectral indices, NBR and NDVI, are adopted to complement the CV and RCVMAX. The NBR has been widely used for monitoring fire disturbance, and NDVI is used for monitoring vegetation condition and vigor. Both NBR and NDVI are less sensitive to topographic and radiometric effects than individual bands because they are ratios of spectral bands. Both indices are believed to be associated with some important biophysical parameters and are more sensitive to forest regeneration and disturbances such as forest harvest and forest fire. The differences between two date NBR and NDVI (i.e., dNBR and dNDVI) will indicate not only the change magnitude but also the change direction. A greater positive value indicates a higher possibility of biomass decrease (i.e., lower greenness in a later date image) and a greater negative value indicates a higher possibility of biomass increase (i.e., higher greenness in a later date image).

Here, a multi-index threshold approach (i.e., MIICA) was developed to define pixels of either BI or BD by simultaneously examine the multiple thresholds as determined by the magnitude of each change index described in Eqs. (1)-(4). The use of multiple thresholds is necessary to examine the consensus of change determined by all spectral change indices. The MIICA model calculates global means and standard deviations for dNBR, dNDVI, CV, and RCVMAX, then sorts each index into several ranks/classes according to the spectral distance from their global means using the standard deviation as a measure unit. Next, a set of specific thresholds for the four indices and integration rules are used to determine the change location and direction between the time periods. For this study, the thresholds are determined empirically through a comprehensive test in areas with diverse land cover and land use types within the conterminous U.S.

Within the MIICA model, the integration rules (i.e. conditional statements) are designed to take advantage of the strength from each index with the goal of minimizing the omission error in detecting real land cover changes while limiting the commission error. For example, one integration rule requires CV be greater than its global mean, RCVMAX be greater than its global mean plus 0.75 times its global standard deviation, and dNDVI be less than its global mean minus 0.5 times its global standard deviation to label a pixel as BI class. Another example of the integration rule to labels a pixel as $\mathrm{BI}$ is that if the pixel's CV is greater than its global mean, RCVMAX is greater than its global mean plus 3.0 times its global standard deviation, and dNDVI is less than its global mean.

\subsection{Zone of $d N B R$ and dNDVI change detection method}

The ultimate goal of MIICA model is to capture a full range of land cover disturbance patterns to update the land cover and land use condition. However, in its current form, the MIICA may fail to capture subtle or gradual change such as forest regeneration, especially for regions with a fast forest succession. As a result, it can miss partially or entirely some changed patches. To compensate for the weakness of the MIICA, a Zone method is introduced by using dNBR and dNDVI only. The dNBR and dNDVI are not only sensitive to the magnitude of the related forest change but also to the direction of the change, and both indices reflect those changes for forest in the same systematic way, which is not always the case for agricultural lands and water. We used these characteristics and developed a model, called "Zone," to strengthen mapping forest regeneration and disturbances including forest harvest, forest fire, and other agent that may lead to land cover conversion from the forestland.

To implement the Zone model (Fig. 3), we divide dNBR (and dNDVI) into four zones according to its magnitude (standard deviation from mean) and direction (positive or negative deviation from mean). The four zones are: 1) pixels with biomass decrease and the dNDVI (or dNBR) exceeds its mean and is less than its mean plus 0.5 standard deviation, 2) pixels with biomass increase and the dNDVI (or dNBR) is less than or equal to its mean and greater than its mean minus 0.5 standard deviation, 3 ) pixels with biomass decrease and the dNDVI (or dNBR) exceeds its mean plus 0.5 standard deviation, and 4) pixels with biomass increase and the dNDVI (or dNBR) is less than its mean plus 0.5 standard deviation. The zones from dNBR and dNDVI are then combined to obtain an image with a total of 16 zones. We then designate the zone with high-order magnitude and the same positive direction from both dNBR and dNDVI as BD class (i.e., zone 44) and the zone with high-order magnitude and the same negative direction from both dNBR and dNDVI as BI class (i.e., zone 33).

\subsection{Combination of change outputs}

\subsubsection{Knowledge-based combination}

As discussed in Sections 3.2 \& 3.3, for each Landsat path/row footprint, four change maps from two image pairs are generated by the MIICA and Zone models. This section addresses the issue of how to combine those changes to obtain a reasonable change map without introducing large commission errors while minimizing omission errors.

Fig. 4 shows a flowchart for the combination procedure. During the combination process, we stratified land cover types into "stable" and "dynamic" groups based on the prior knowledge of land cover land use change history to assist reasonable integration. Some spectral changes shown in stable group are likely associated with phenology or seasonal change, but unlikely the true land cover change if the spectral change is identified by only one change pair. In contrast, spectral changes shown in dynamic group are likely to reflect true

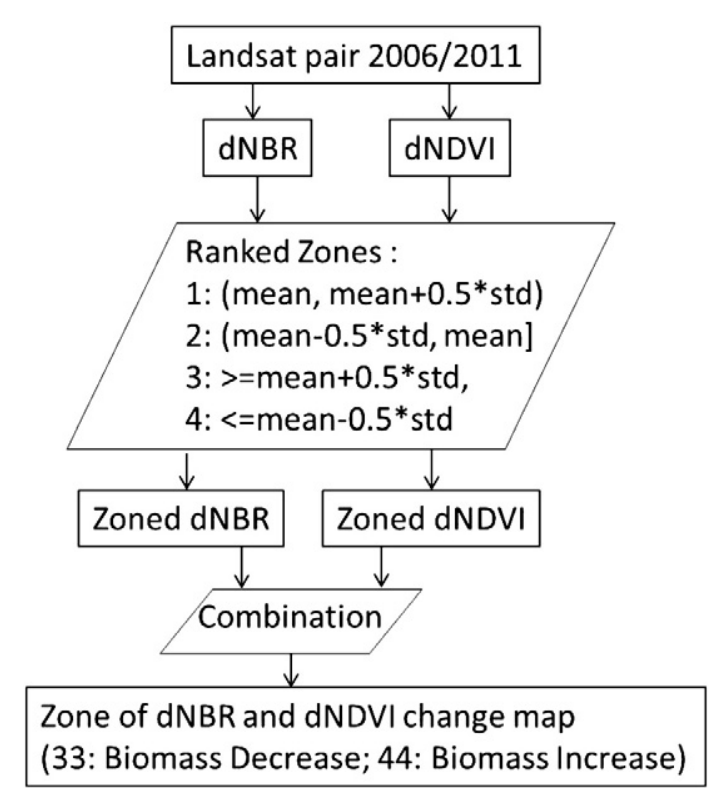

Fig. 3. The flowchart of Zone model. 
land cover change if the change is identified by either change pair Therefore, two general rules are created for different cases based on land cover types (group). The general rule "AND," which requires both change pairs to agree (as changes), will be used for combining changes for the "stable" group (likely phenology and seasonal changes) to minimize commission errors. The general rule "OR," which counts a pixel as a change if change is detected from either pair, will be used for combining changes for the "dynamic" group (likely true land cover change) to minimize omission errors. When "OR" is applied, the change direction is determined by the early-date change pair first, then by the late-date change pair. Here, the early date is determined by the images of circa 2006.

We use NLCD 2006 to categorize the land cover into the above two groups. The "dynamic" group includes forests, shrub, herbaceous, and woody wetlands, and the "stable" group includes the rest of the land cover classes. For some regions, especially the western United States, there are large areas of persistent herbaceous and shrub classes rather than the intermediate successional stage of forests seen in the eastern United States. These two persistent herbaceous and shrub classes are likely to experience phenology or seasonal changes but unlikely to have true land cover changes; therefore, they are more appropriately included in the "stable" group. To define this particular group, we add NLCD 2001 in addition to NLCD 2006 to create a mask of persistent herbaceous and shrub classes. The herbaceous and shrub areas where both NLCD 2001 and NLCD 2006 agree are counted as persistent herbaceous and shrub classes. For change analysis in many areas in the western United States, we recommend to use this revised category.

As mentioned in Section 3.3 that the Zone model was particularly designed for forest-related change as a complementary method for MIICA, therefore we use the "dynamic" group to create a thematic mask to derive changes for related forest classes. We also mentioned in Section 3.3 that the Zone method is sensitive to subtle change and especially suitable for area with fast-growing vegetation; therefore, change results from the Zone model are strongly recommended to be combined with MIICA change map for those regions, e.g. for the southeastern United States. Users have the option not to use Zone according to the condition of each study area.

\subsubsection{Trajectory-based combination}

3.4.2.1. Combination rule. Logical trajectory information, in addition to land cover condition, is another natural choice to be employed to assist reasonable integration for change detection (Fig. 5). Commission errors in change detection can be further reduced by the logical analyses using the trajectory information. For example, if a pixel was correctly classified as forest type in NLCD 2006 and identified as BI class between 2006 and 2011, it is likely that the land cover type of the pixel should remain as forest for NLCD 2011. However, this is based on the assumption that the land cover label from NLCD 2006 is correct, which may or may not be always true. To ensure that we did not omit real change due to a possible labeling error in NLCD 2006 (base error), we introduced a concept using the Normalized Spectral Distance (NSD) to identify the potential base error from NLCD 2006. The NSD represents the spectral distance of each Landsat pixel to the mean spectral signature of a land cover type it belongs to (see Section 3.4.2.2 for detail). Specifically, for a given forest pixel that has been identified as BI from 2006 to 2011, only when it is highly unlikely to be mislabeled in NLCD 2006 (i.e., both NSDs from two Landsat images of circa 2006 are lower than a set of threshold), we then apply the logical trajectory information and convert the pixel from the change class back to no-change class. The same rule is applied to the woody-wetland class. For the persistent herbaceous and shrub classes in the western United States, most spectral changes are likely to be caused by phenology and weather, which is not necessarily related to real land cover change. In this case, we use not only two NSDs from 2006 to ensure that no base error from NLCD 2006 is involved but also two NSDs from 2011 to further confirm that those areas can still be reasonable classified as herbaceous or shrub classes in 2011. Four NSDs are used to remove spurious changes related to persistent herbaceous and shrub in the western United States. A final maximum potential spectral change map is produced after the trajectory-based combination for a Landsat path/row and to be used for the NLCD 2011 second stage (classification) process.

3.4.2.2. Normalized Spectral Distance (NSD). NSD represents the spectral distance of each Landsat pixel to the mean spectral signature of a land cover type it belongs to (Eq. (5)):

$\mathrm{NSD}=\sum_{i}\left[\left(B_{i}-\mu_{i c}\right) / \sigma_{i c}\right]^{2}$

where $i$ is band number, $\mathrm{c}$ is the land cover type, $B_{\mathrm{i}}$ is the ith band of Landsat image, and $\mu_{\mathrm{ic}}$ and $\sigma_{\mathrm{ic}}$ are the mean and standard deviation of the ith band of the Landsat image over the c land cover type area, respectively.

The concept of NSD is the same as Z-statistic. Z-statistic compares the pixel's actual spectral value with the "expected" value. All pixels belong to a particular class are collected to determine the expected average spectral response and standard deviation of the class. We used NLCD 2006 to segregate a circa 2006 Landsat image into distinct class zones. A high NSD will occur when a pixel appears very different from the class average and is, therefore, highly likely to have been classified wrong. The NSD is used to identify potential/suspicious base error of NLCD 2006.

\subsection{Accuracy assessment method}

To evaluate the output of the maximum potential spectral change map derived from the CCDM process, an accuracy assessment was

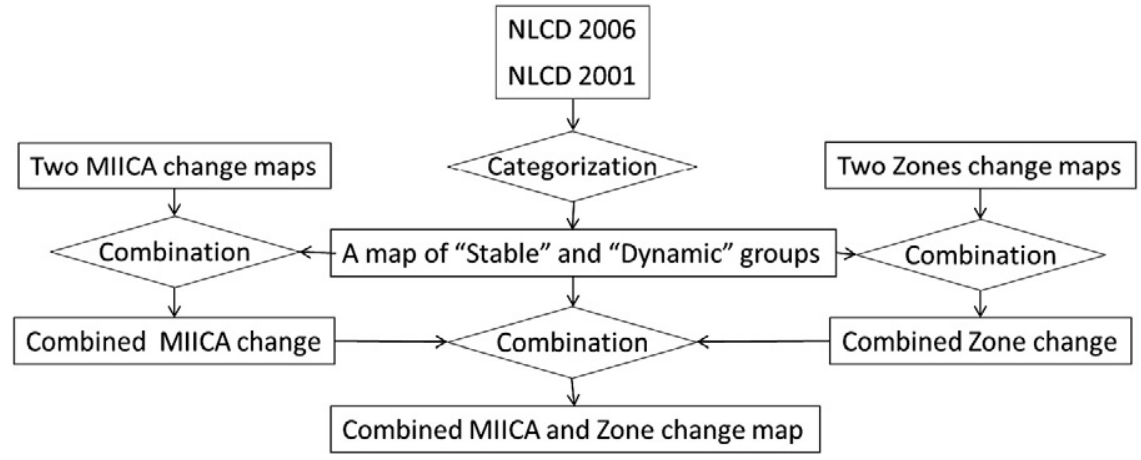

Fig. 4. The flowchart of the knowledge-based combination of change maps derived from the MIICA and Zone methods. 


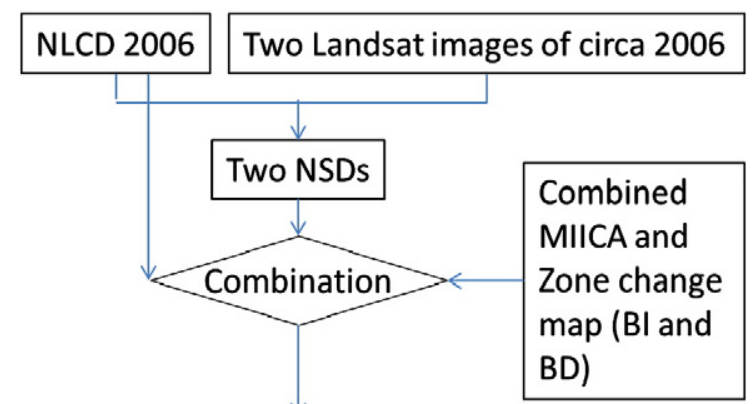

Maximum potential spectral change map

Fig. 5. The flowchart of trajectory-based combination.

conducted including a statistical sampling procedure, an interpretation protocol for selected samples, and computation of accuracy parameters.

An equalized random sampling procedure was applied to obtain samples for the assessment, in which two strata (change and nochange) were formed. Fifty sample units ( 3 by 3 Landsat pixel kernel) were randomly drawn from each stratum and used to assess the quality of the change detection results. For each sample unit, visual interpretation by two trained persons was conducted by examining 2006 and 2011 Landsat images and corresponding high resolution images (from Google Earth and United States Department of Agriculture National Agriculture Imagery Program images) to determine if land cover had changed from 2006 to 2011. Our protocol for assessing the change and no-change accuracy of the change product is based on change of land cover type rather than the spectral change. Therefore, a change sample can be counted as correct only when actual land cover type change occurs. In some cases, the difference in image acquisition time and year between high-resolution and Landsat images can affect the decision for labeling the land cover of the sample unit. In such cases, interpretation from the Landsat images was used as the primary source to determine the final land cover label for that sample.

The results from the sampling and interpretation process provide a complete reference dataset for accuracy assessment. This reference dataset was then used to compute the accuracy parameters for each of the two study areas.

\section{Application of the CCDM and results}

\subsection{Study area, data, and general procedures for change detection}

To demonstrate the performance of the comprehensive change detection method, we showcase the results from two Landsat path/ rows (p22r39 and p33r33), which are different in landscapes and represent the two different yet complete set scenarios (i.e. decision rules) designed in the CCDM. The first Landsat path/row (22/39) is located in Louisiana and Mississippi (Fig. 6), and the center coordinates of the scene are $30^{\circ} 17^{\prime} 42.48^{\prime \prime} \mathrm{N}$ and $90^{\circ} 08^{\prime} 43.50^{\prime \prime} \mathrm{W}$. According to NLCD 2006, the area is dominated by woody wetlands (23.56\%), open water (20.46\%), and evergreen forest (13.05\%). Agriculture, urban, shrub, and herbaceous account for $10.33 \%, 8.20 \%, 8.07 \%$, and $2.82 \%$ of the area, respectively. Forest vegetation in this area often experiences fast growth with a short harvest cycle because of high temperature and humidity during most of the year. For this path/row, Zone change detection results in addition to MIICA were combined to derive the maximum potential spectral change map.

The second Landsat path/row (p33r33) is located in Colorado. The center coordinates of the image are $38^{\circ} 53^{\prime} 52.47^{\prime \prime} \mathrm{N}$ and $104^{\circ} 39^{\prime}$ $58.55^{\prime \prime} \mathrm{W}$. The area is dominated by herbaceous (53.71\%), evergreen forest (20.93\%), and shrub (10.82\%). Urban, agriculture, wetland, and water account for $6.57 \%, 4.34 \%, 1.43 \%$, and $0.31 \%$ of the area, respectively. The majority of herbaceous and shrub are persistent late successional vegetation rather than early succession stage of the forests. The forests experience slow growth and the main disturbance of the forests is from wildland fire without much forest harvesting activity. Vegetation phenology can vary significantly from year to year depending on temperature and precipitation. Hence, for this area, results from Zone were not used to compensate for the MIICA results, and four NSDs were used to assist in reducing commission errors.

\subsection{Change detection results}

\subsubsection{Landsat Path22/Row39}

The two Landsat image pairs selected for p22r39 were acquired on 2005/02/11 vs. 2009/02/06, and on 2006/10/28 vs. 2010/11/08. Fig. 7 shows the intermediate and final results from the comprehensive change detection methodology for the subset- 1 area, which is dominated by forests and woody wetland. Specifically, Fig. 7 comprises two Landsat change pairs, four indices calculated from each change pair, two MIICA and two Zone change maps, NLCD 2006, NSDs, and combined change maps. Forest related changes, such as forest harvest and regrowth, are the primary changes that occurred between the two time periods for the subset- 1 area. CV and RCVMAX characterize change magnitude in one direction, i.e. a higher value indicates larger spectral change and, therefore, a higher possibility of change. Both CV and RCVMAX highlight the general change pattern, and RCVMAX seems to show the related forest change more apparently than CV. Both dNBR and dNDVI demonstrate a very similar change pattern and show both magnitude and direction of change (high value for $\mathrm{BD}$ and low value for $\mathrm{BI})$.

Because a large proportion of forest harvest occurred between 2005/02/11 and 2006/10/28, the MIICA and Zone change map of the early-date pair shows the opposite change direction to the change derived from the late-date pair for those change areas (Fig. 7). For the same area, BD seems to be more readily captured than BI because the change magnitude of BD is larger than BI. For those gradual forest changes, the Zone model captures the change patches more completely than the MIICA. Therefore, the related forest changes from the Zone model are integrated with MIICA results to reduce omission errors for this Landsat scene. The land cover from NLCD 2006 matches the Landsat image of 2005/02/11 better than the Landsat image of 2006/10/28 for this subset area, which is indicated by NSD. NSD of the $2006 / 10 / 28$ image shows that several big patches are not likely to be in forest stage, which can be interpreted from the two Landsat images of circa 2006 (areas harvested in between 2005/02/11 and 2006/10/28). We noted that NLCD 2006 for the path/row p22r39 was derived using an image acquired between 2005/02/11 and 2006/10/28. The final maximum spectral change map (combined_2MIICA_2Zone_2NSD) removes the majority of white pixels (i.e., forest in 2006 and biomass increase during the period) from the change map of combined_2MIICA_2Zone, because the combined NSD does not identify those pixels as being likely misclassified.

The subset-2 area (Fig. 8) demonstrates the change-detection method and procedures for a landscape mixed with forest, woody wetland, and agricultural land cover types. MIICA and Zone capture changes that occurred in forest and woody wetland areas pretty well and show a similar pattern; however, the change patches detected by Zone are slightly fuller than the changes patches from MIICA. The early-date and late-date pairs show different change patterns and compensate for each other. For example, the BD patch in the lower-left corner is detected in the early-date pair but missed in the late-date pair, and a sliver of BD change of woody wetland (left-center) is missed in the early-date pair but picked up as BI in the late-date pair. Using the "OR" combination rule for forest area, the omission error was reduced by combining two change outputs from the MIICA. For agricultural lands that likely have large spectral change but not real land cover change, use of "AND" combination 


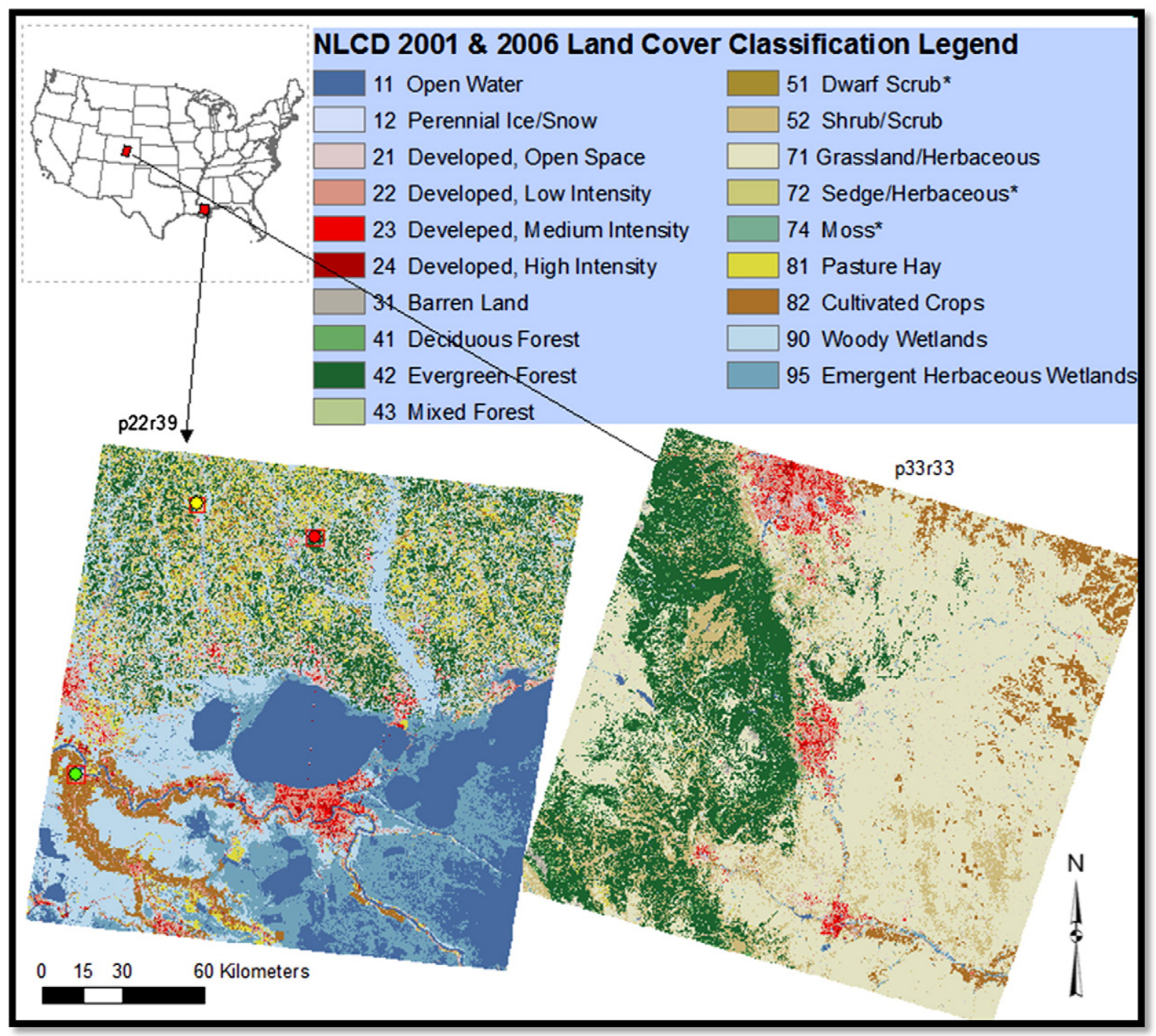

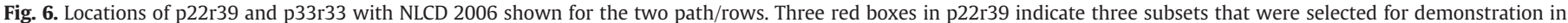

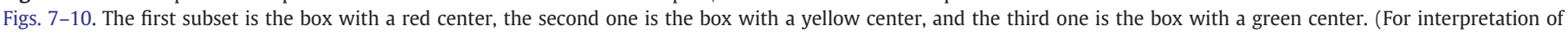
the references to color in this figure legend, the reader is referred to the web version of this article.)

rule reduced commission error by combining two outputs from the MIICA. There are two big white patches (forest or woody wetland in 2006 and biomass increase during the time period) in the change map of Combined_2MIICA_2Zone. One (upper-left corner of the subset-2) is removed and the other one (lower-left) is kept through the NSD integration procedure because NSD only identifies the lower-left patch as most likely being misclassified in NLCD 2006 but not the upper-left one (classified as woody wetland in NLCD 2006). Fig. 9 shows the transitional change for these two patches using aerial photos from the Google Earth. Both patches experienced BI change between 2006 and 2010; however, the upper-left patch was harvested before 2005 and the lower-left patch was harvested between 2005 and 2006. NSD was not able to distinguish the upper-left patch possibly because the vegetation grew back a little after harvest and the woody wetland class has a wide spectral range.

The subset-3 area (Fig. 10) is mainly composed of cultivated crops, water, woody wetland, and urban. Agriculture areas are likely to be identified as change because of large spectral change due to crop rotation, irrigation, and seasonality. Each MIICA captures those apparent spectral changes on agriculture lands, and those spurious land cover change pixels are greatly reduced after the combination of the two MIICA outputs. CV is not sensitive to water turbidity and has a low value for water bodies, which helps in identifying the water boundary, while RCVMAX shows a large variation within water bodies. Water boundary change is kept but the woody wetland change due to variation in moisture is removed through the NSD integration step.

\subsubsection{Landsat Path33/Row33}

The two Landsat image pairs selected for p33r33 were acquired on $2005 / 10 / 22$ vs. $2011 / 10 / 23$, and on 2007/09/26 vs. 2011/08/20. Fig. 11 shows the intermediate and final results from the comprehensive change detection methodology for a subset area, which is dominated by persistent grassland and forests. A major proportion of the subset area was identified as change either by MIICA or Zone, which is likely caused by phenology difference between two time periods. Zone change was not included in the final change because the grassland condition in the western United States is sensitive to weather and seasonal variations, and many spectral changes are not associated with real land cover change. The combination of two MIICAs kept the overlap change area from each individual MIICA and reduced a large amount of commission errors compared to the single MIICA output of the early-date pair. The use of four NSDs derived from the four Landsat images further removed a large portion of spurious changes according to the logical 
trajectory integration rules. Fig. 12 shows a subset area with a fire disturbance that occurred between 2007 and 2011. The patch that experienced fire disturbance survived through all the change detection steps, while many spurious change pixels were removed through the processing procedure.

\subsection{Accuracy assessment results}

Table 1 shows the accuracy assessment results for p22r39. A total of 100 sampling units $(3 * 3$ pixel kernel) were randomly drawn from the two strata (i.e., change and no change), 50 units from each stratum. The land cover types of these 100 units are mainly forests, woody wetland, herbaceous, and water classes. The majority of the samples from the change stratum are located in forested and herbaceous lands, which indicates that the main change process observed from this Landsat path/ row is related to forest harvest and regrowth. Among the 50 samples from the change stratum, nine were considered to have no real land cover (or land use) change during the time period 2006-2011. All 50 samples drawn from the no-change stratum were identified as no land cover change, so there is no omission error.

As discussed in the Methods section, our protocol for assessing the change and no-change accuracy of the MIICA change product is based on change of land cover type rather than the spectral change alone. Therefore, a change sample is counted as correct only when actual land cover type change occurs. This protocol has some limitations because it does not account for some gradual changes due to forest succession, treatment and harvest processes (e.g., regrowth, commercial thinning, or partial cut). In fact, we noted that 7 out of 9 samples of change that were identified as incorrect (no land cover change) could be considered correct if gradual changes are counted. Fig. 13 shows two examples from these seven "incorrect" samples. Sample A shows very recent plantations (classified as shrub based on height) in 2006 which grew much taller and denser in 2010; however, it is still classified as shrub based on height. Sample B shows a dense forest in 2006 which was thinned in 2010; however, it is still a forest cover type despite obvious change spectrally. The remaining two samples from the nine samples identified as incorrect are located within a grassland and a hay/ pasture field. For this path/row p22r39, there is $100 \%$ agreement between the CCDM mapped no-change class and the reference dataset, $18 \%$ disagreement for change class, and the overall agreement is $91 \%$. If we count these seven samples as correct, the disagreement for the change class will decrease from $18 \%$ to $4 \%$.

Table 2 shows the accuracy assessment results for p33r33. There is $100 \%$ agreement for no-change class, and $88 \%$ disagreement for the change class. In this path/row footprint, there is little change in land cover and the vegetation growth rate is generally low. Fourteen out of sixteen herbaceous samples and all seventeen agriculture samples for change class were identified as no change in terms of land cover/land use change. The change method did capture several fire disturbances, forest thinning events, and vegetation regrowth over the fire scar areas.

\section{Discussion}

From this research, a comprehensive change detection method (CCDM) was designed and implemented to capture a full range of land cover land use changes, including disturbances and alteration of land use practices, which can lead to many land cover changes. Furthermore, we also intend to capture the gradual or subtle changes (e.g., regeneration after forest harvest) for two reasons. First, some of those gradual changes could eventually lead to land cover changes under certain conditions. Second, the information on gradual changes can be of great value to some data users and has been and will continue to be made available as a component of the NLCD product (e.g., a maximum potential spectral change product in NLCD 2006). This maximum potential spectral change product has been integrated with land cover classification results to derive a final thematic land class change product.

Cohen et al. (2010) stated that change detection using Landsat imagery is undergoing a major paradigm shift due to the convergence of a need for more temporally detailed information over larger areas, the free availability of Landsat data from the U.S. archive, and the emergence of automated Landsat time series algorithms. Automated algorithms like LandTrendr (Kennedy et al., 2010) and Vegetation Change Tracker (VCT) (Huang et al., 2010) have been successfully developed to exploit the Landsat archive by taking advantage of high temporal densities of data that enhance a relatively low signal-tonoise ratio commonly associated with comparing lower temporal density datasets. However, both LandTrendr and VCT were initially targeted primary for forest-related disturbances and are not designed for detecting all land surface changes of many other terrestrial ecosystems (e.g., shrub, herbaceous, cropland). For NLCD 2011 national implementation that will update land cover condition and provide information on land cover changes between 2006 and 2011, we need a simple but comprehensive semi-automated change detection method to achieve the efficiency in operation while maintaining quality of the products.

The CCDM developed through this research comprises three parts: MIICA, Zone, and Combination. Among them, the MIICA is the core module of the change detection strategy and uses four spectral-based indices ( CV, RCVMAX, dNBR, dNDVI) to generate a change product between two image dates. Comparing results obtained using a single CV (see Xian \& Homer, 2009), we concluded that the MIICA approach has significantly reduced commission error while increasing the sensitivity to real disturbances. This conclusion is supported by results from both this pilot study and those from the NLCD 2006 production operation throughout the conterminous United States (Fry et al., 2011). The two case studies shown in the paper indicate that the MIICA is robust in capturing various types of land disturbance processes with very low omission errors. However, sometimes substantial areas of solid change patches detected by MIICA involve only spectral change without actual land cover and land use change between two dates, which more likely occur on certain landscapes (e.g. cultivated crop class with corn in an early date and soybean in a late date) and changing weather conditions (e.g. grassland in a very wet date and a very dry date). The main strength of MIICA is that it can capture the full suite of disturbances that occur within a variety of ecosystems in one simple and efficient process without introducing large commission errors. The MIICA is easy and efficient to operate. One weakness of the MIICA is that it may miss some subtle changes because of the general threshold values set for balancing the commission and omission error. Another weakness is its sensitivity to vegetation phenology and certain land cover types because it is a spectral-based method. The quality of the change

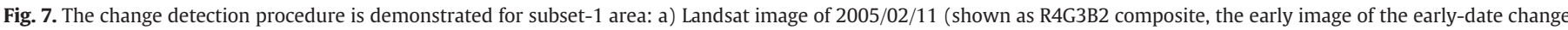

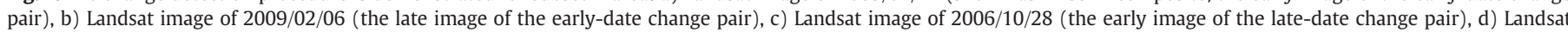

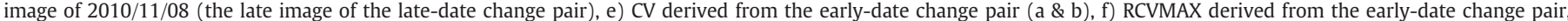

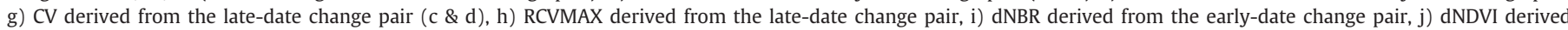

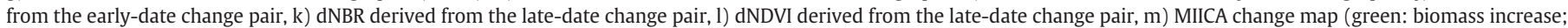

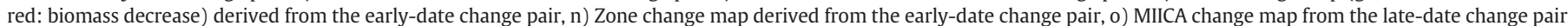

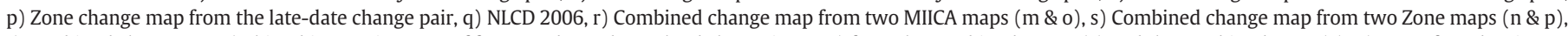

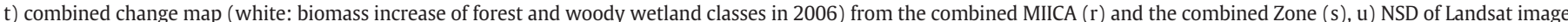

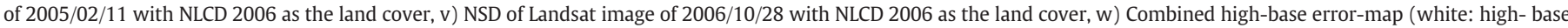

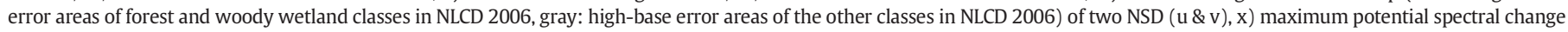
map after the combination of MIICA, Zone, and NSD. (For interpretation of the references to color in this figure legend, the reader is referred to the web version of this article.) 

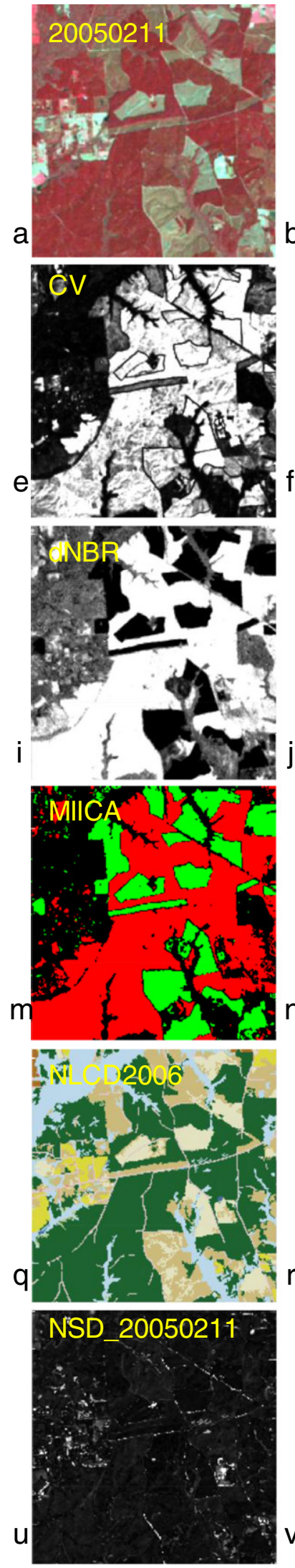
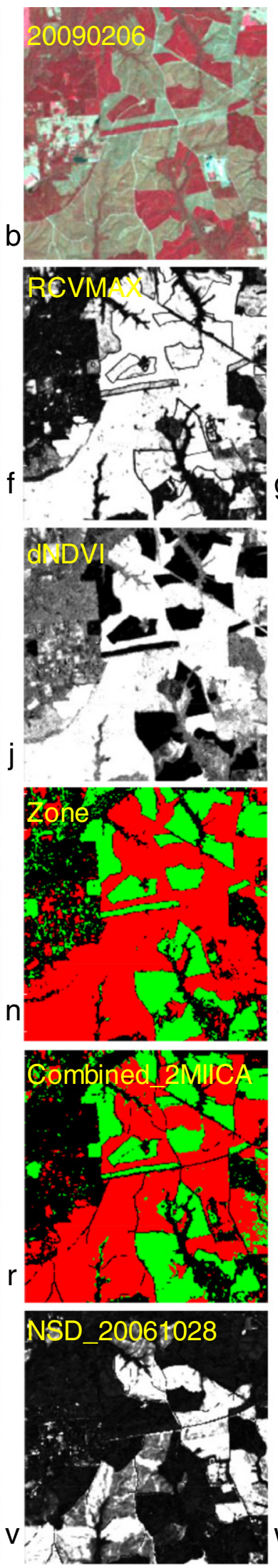
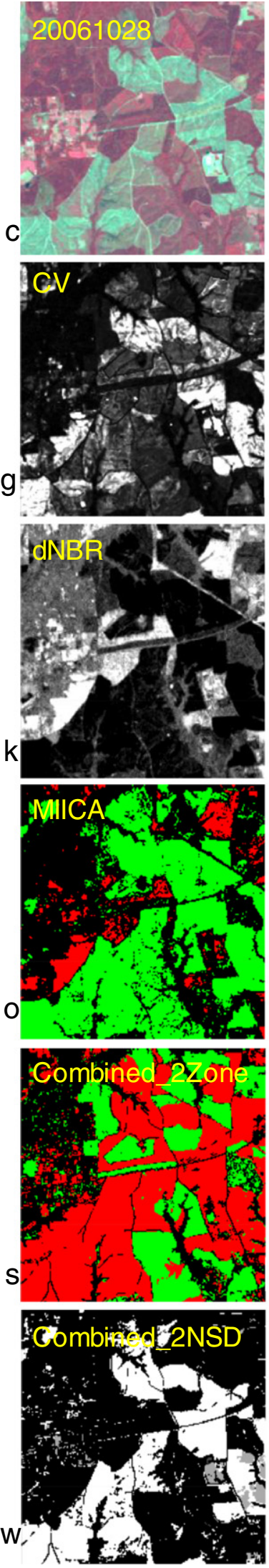
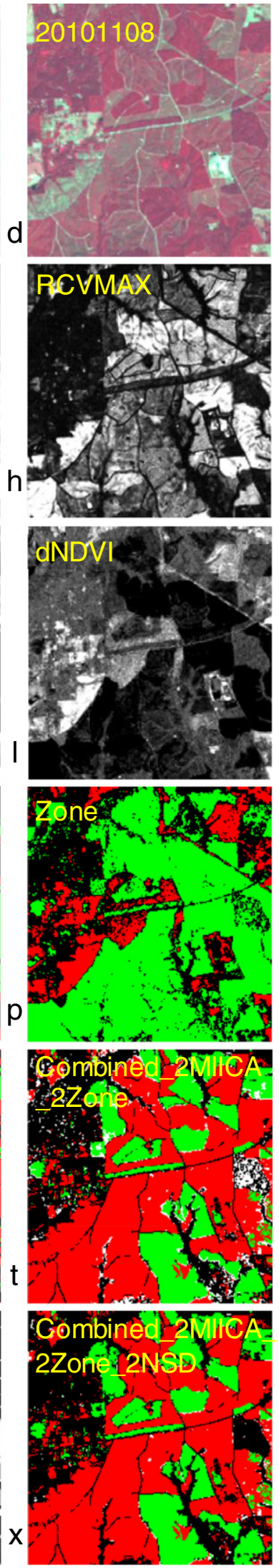

detection output is also affected by the quality of the Landsat images selected. Results from the MIICA alone may include some spurious land cover changes in addition to real changes.
The other two parts of the CCDM (Zone and Combination) have been developed through this study to mitigate the weakness of the MIICA. The Zone uses harmonized sensitivity of dNBR and dNDVI to 

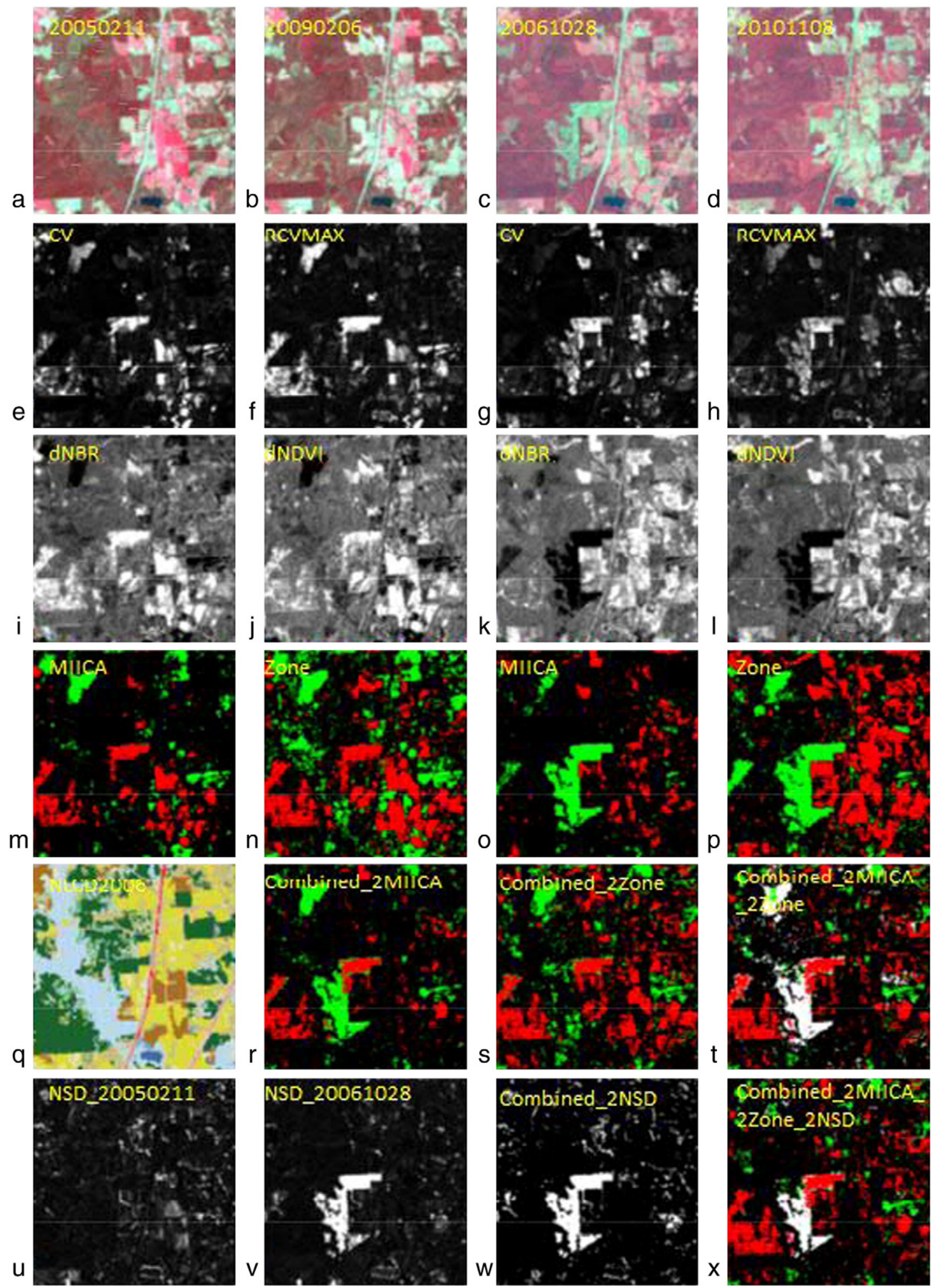

Fig. 8. The change detection procedure is demonstrated for subset- 2 area. The images are arranged in the same order as Fig. 7 .

vegetation change to improve detection of forest changes. The concept of Zone is simple but efficient and was shown to be more sensitive than MIICA in capturing a variety of forest-related changes, including regeneration and regrowth. However, Zone was also sensitive to phenology/seasonal change and changes caused by variations in weather conditions such as a drought. In some of the western United States where grassland and shrubland are the dominant land cover and are less likely to have large area of land cover changes, 

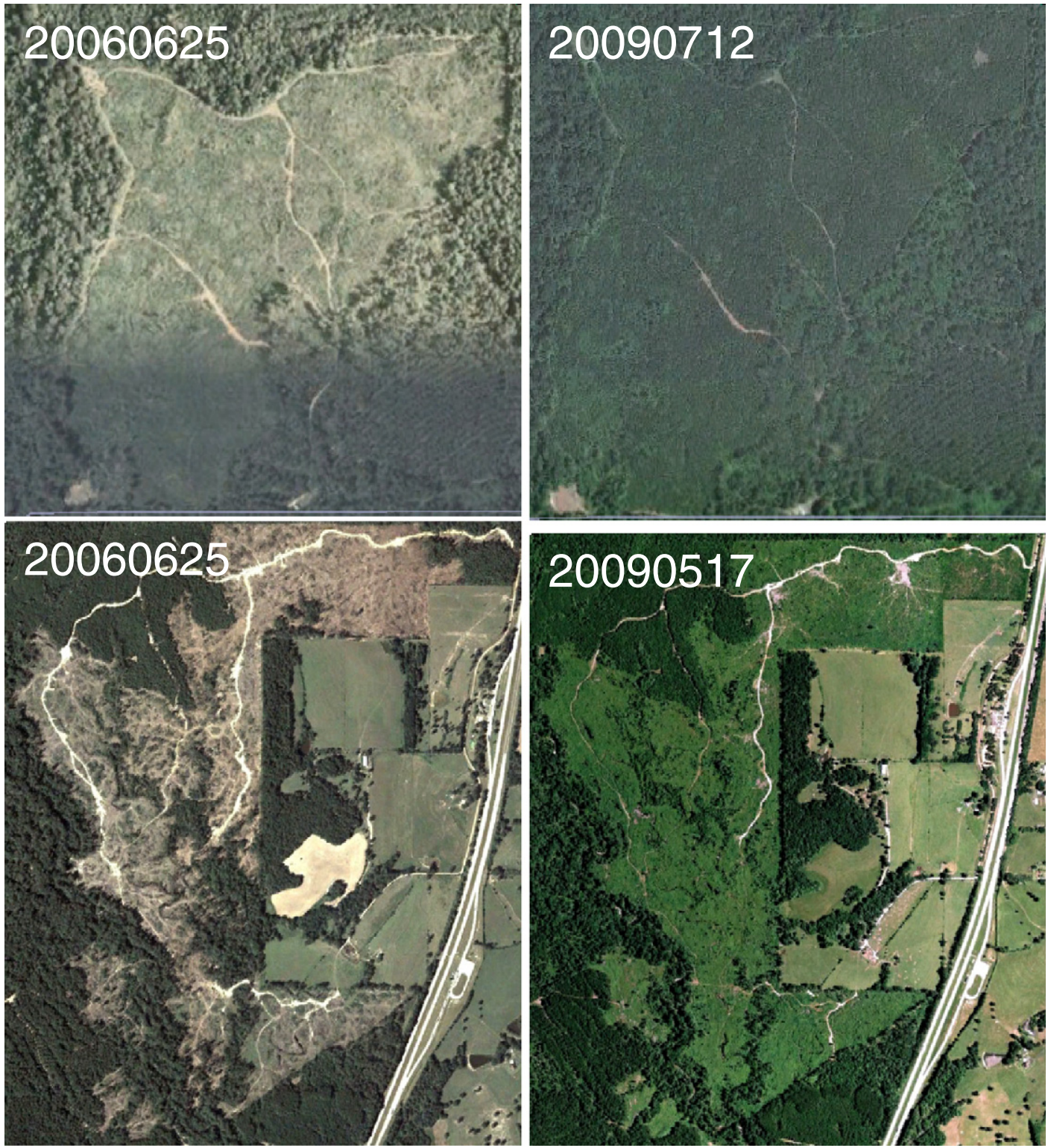

Fig. 9. Aerial photos from Google Earth for the two white patches within subset-2.

we cautioned the use of the Zone in the area in order to avoid having too much commission error. Nevertheless, the strength of the Zone is to capture vegetation changes including subtle changes; therefore, it has great potential in applications in studying forest disturbance and succession such as forest harvest, forest fire, forest insect infestation, and forest regeneration.

This study shows that using two pairs of Landsat images within a season can complement each other and provide additional information for better detecting real land cover change while reducing spurious changes caused by factors such as seasonal change, cloud, snow, and image acquisition time. For example, as shown in the p22r39 subset-2 area (Fig. 8), the early-date pair captured a change patch that occurred between 2005 and 2009, located at the lower-left corner of the subset area, which was missed by the late-date pair because vegetation started to regrow between 2009 and 2010. The additional image pair may provide different information even when the disturbances that occurred between the image dates of the additional pair are the same as another image pair. For example, in the p33r33 subset areas where real change and no change pixels are very similar for two image pairs, the results of
MIICA and Zone from the early-date pair are quite different from the results from the late-date pair.

The addition and use of the combination method aims at retaining more complete disturbance information and further removing the spurious changes from the two change pairs generated from MIICA, i.e. decrease commission and omission errors at the same time. We categorized the land cover types into two groups: the "stable" group-likely phenology or seasonal change but unlikely true land cover change; and the "dynamic" group-likely true land cover change. Accordingly, we combined change results from two change pairs using either AND or OR rules to meet the goal of minimizing commission and omission errors. The results from our test have demonstrated the benefits of combining change results from the two change pairs. Overall, this combination approach is simple and logical and can produce reasonably accurate change product, even though it is not perfect and may lose some real changes (on stable-group Land cover) and/or contain some spurious changes (on dynamic-group land cover). The method does require a good quality land cover baseline dataset available to be used in the combination process. 

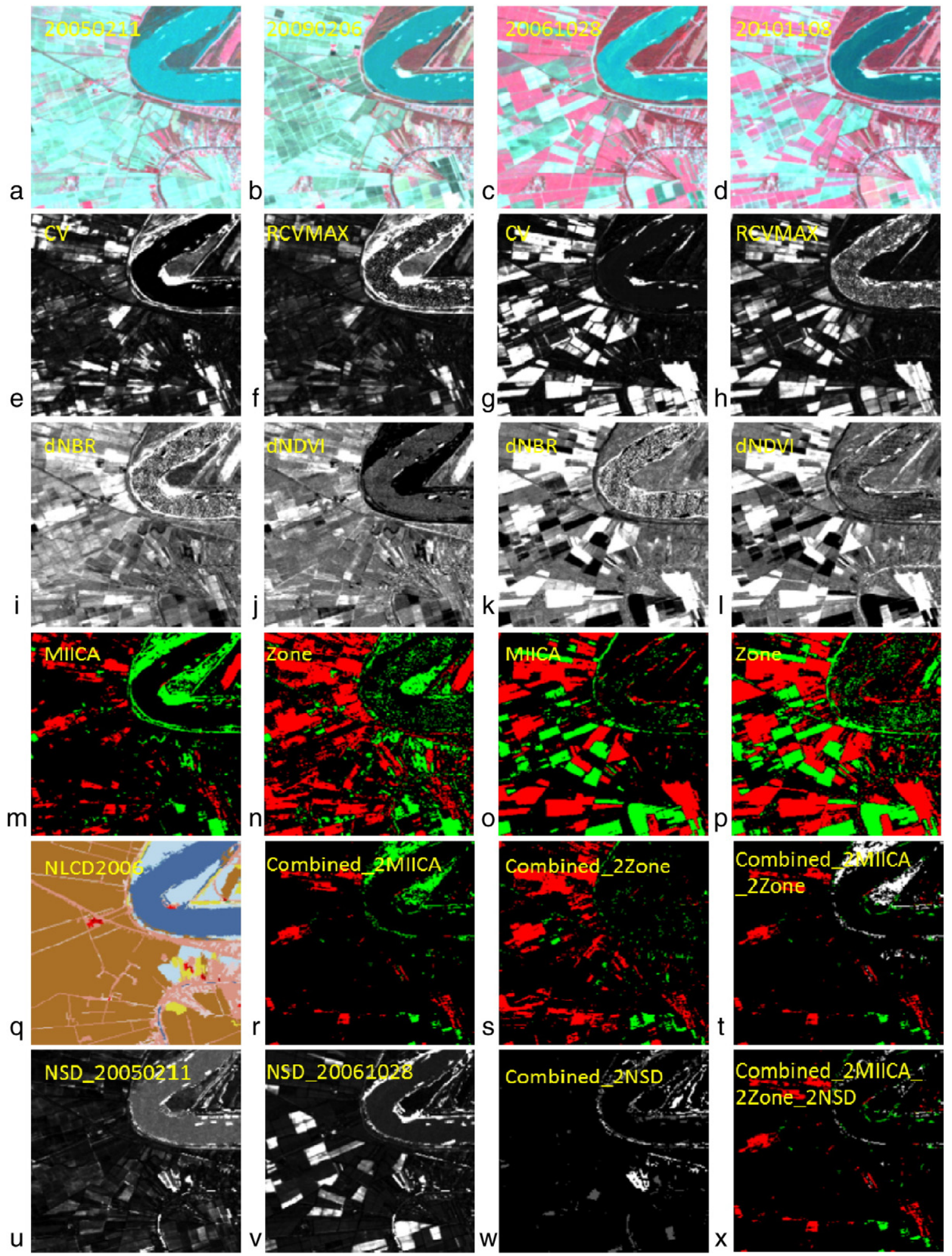

Fig. 10. The change detection procedure is demonstrated for subset-3 area. The images are arranged in the same order as Fig. 7.

An approach using knowledge-based trajectory information in addition to the combination procedure was also explored and is effective in reducing commission errors. To minimize the change detection error which might be caused by NLCD 2006 base error, an NSD metric was developed to identify areas with potential land cover label errors in NLCD 2006. The NSD represents the spectral distance of each Landsat pixel to the mean spectral signature of the land cover type it belongs to. High NSD reflects the incompatibility between the Landsat spectral value and the land cover type. As shown in an example (Fig. 8), NSD derived from the Landsat image of 2006/10/28 highlighted several patches where forests were harvested between 2005/02/11 and 2006/10/28. Later, it was confirmed that a Landsat image of 2005 was used for 
a

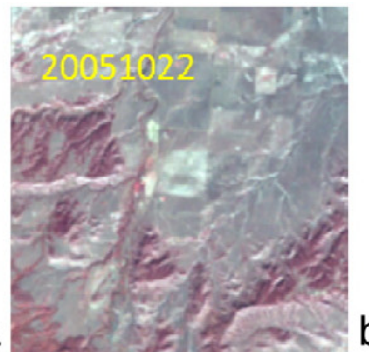

e
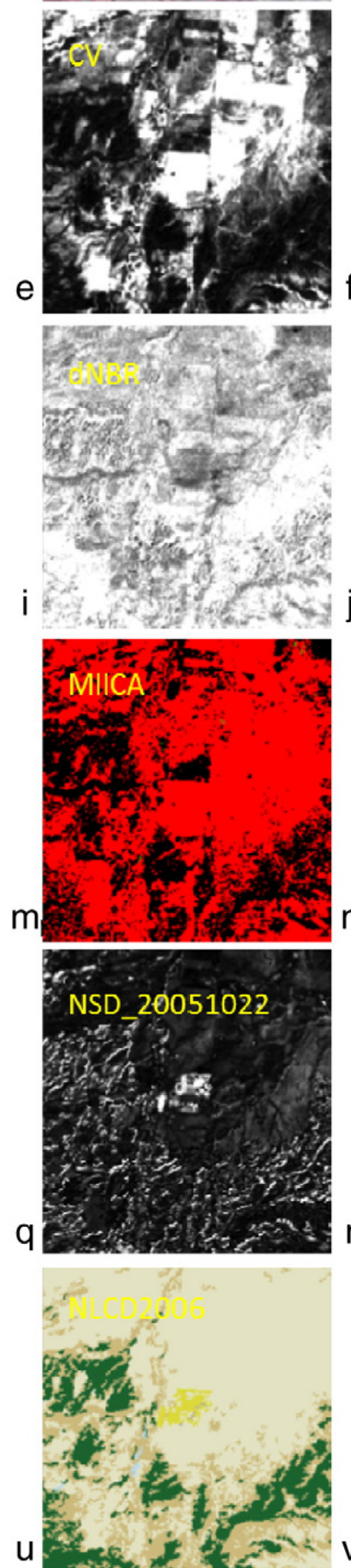
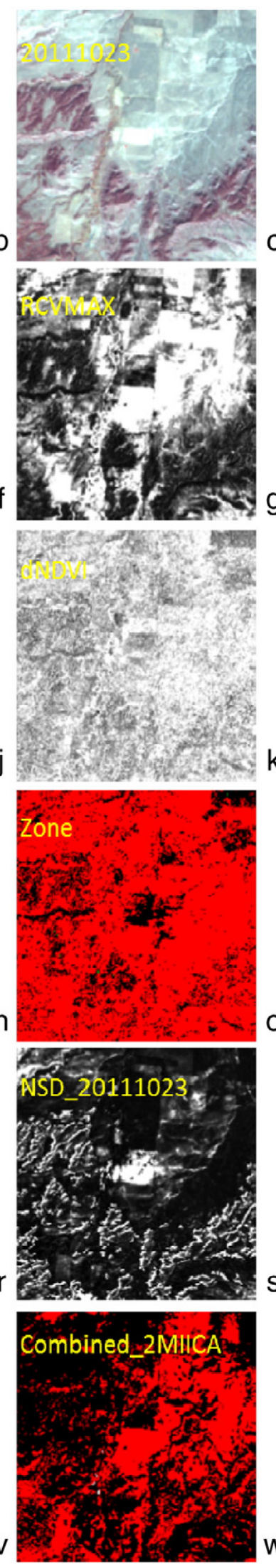
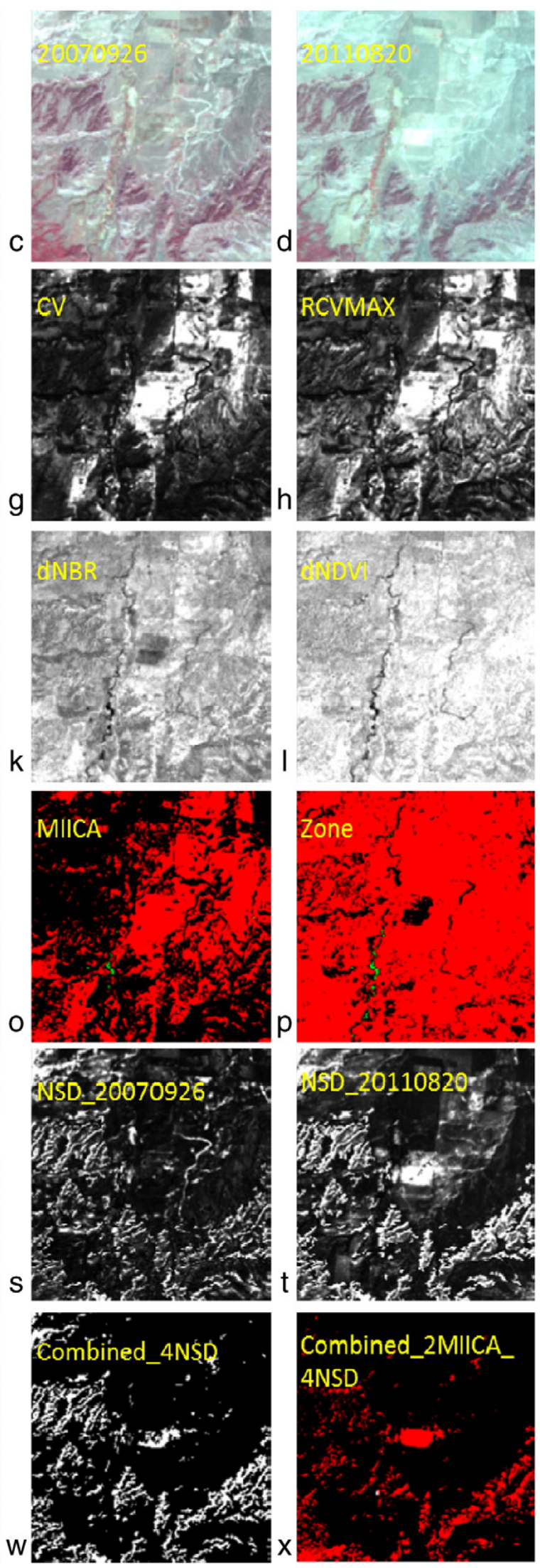

Fig. 11. The change detection procedure is demonstrated for a subset of $\mathrm{p} 33 \mathrm{r} 33$.

NLCD 2006 mapping for p22r39. The NSD provides a reasonable overview of areas with a high risk of being classified incorrectly; however, NSD can be of limited use for some land cover types that exhibit a wide spectral range (e.g., agricultural classes). After excluding the high-risk areas using NSD, some change pixels were removed through the logical trajectory analysis, which indicates the area that land cover 

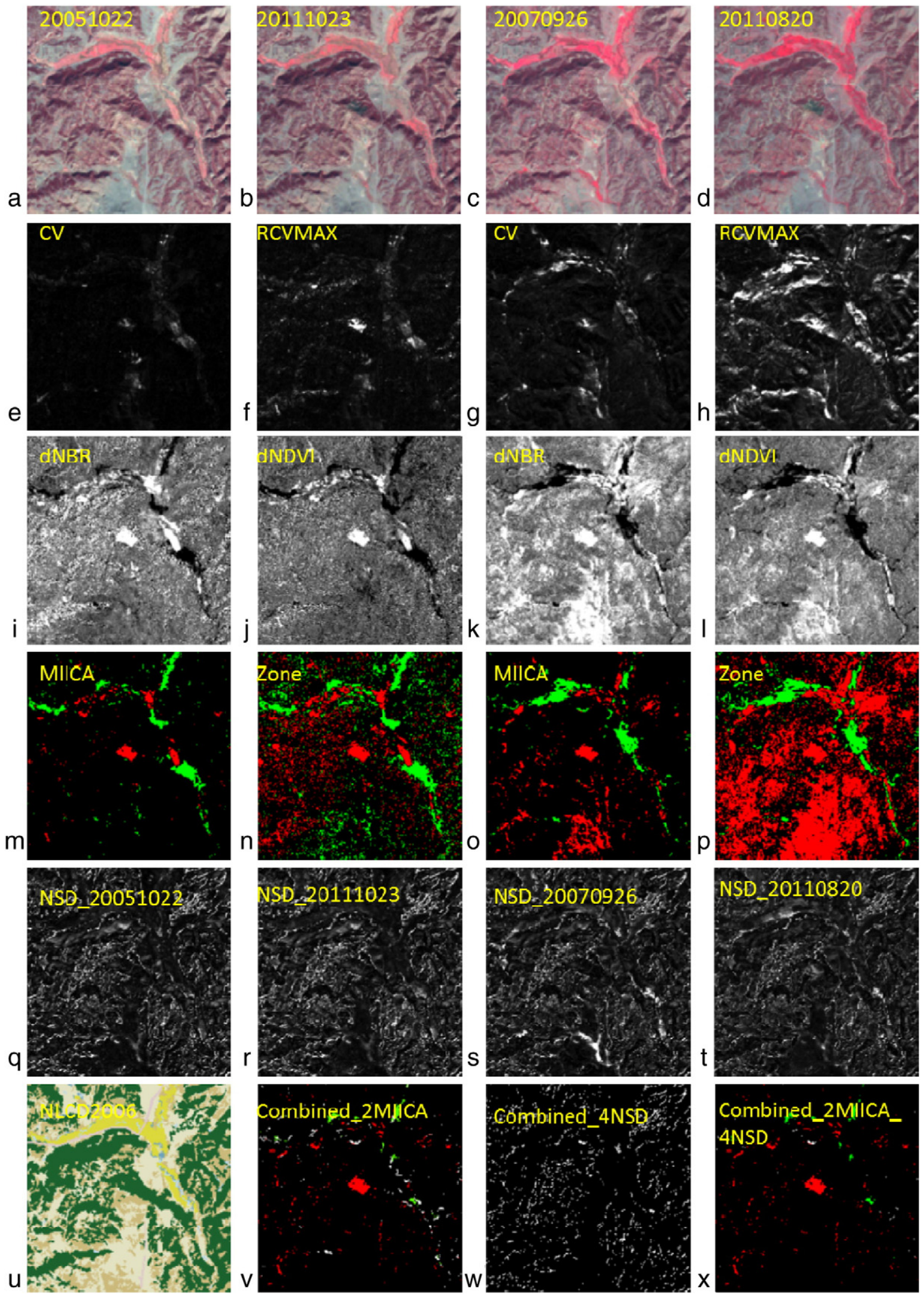

Fig. 12. The change detection procedure is demonstrated for another subset area of p33r33.

changes were unlikely to occur. In p33r33, for example, we observed that a large amount of spurious change pixels were removed while the true land cover changes were preserved.
Capturing land cover change information accurately with remote sensing over many types of ecosystems and large area geographies remains a very complex task. While not entirely automated yet, we 
Table 1

Accuracy assessment results of 100 samples for p22r39.

\begin{tabular}{|c|c|c|c|c|c|}
\hline \multirow[t]{2}{*}{ NLCD2006 (class name/code) } & \multirow[t]{2}{*}{ Number of samples } & \multicolumn{2}{|c|}{ Change between 06 and 11} & \multicolumn{2}{|c|}{ No change between 06 and 11} \\
\hline & & Sample \# & Disagreement \# & Sample \# & Disagreement \# \\
\hline Water (11) & 15 & 0 & 0 & 15 & 0 \\
\hline Urban $(21,22,23,24)$ & 5 & 0 & 0 & 5 & 0 \\
\hline Forests $(41,42,43)$ & 24 & 21 & 4 & 3 & 0 \\
\hline Shrub/scrub (52) & 7 & 6 & 1 & 1 & 0 \\
\hline Grassland/herbaceous (71) & 16 & 16 & 2 & 0 & 0 \\
\hline Pasture hay (81) & 6 & 0 & 0 & 6 & 0 \\
\hline Cultivated crops (82) & 4 & 1 & 1 & 3 & 0 \\
\hline Woody wetlands (90) & 17 & 6 & 1 & 11 & 0 \\
\hline Emergent herbaceous wetlands (95) & 6 & 0 & 0 & 6 & 0 \\
\hline Sum & 100 & 50 & 9 & 50 & 0 \\
\hline Disagreement percentage & & & $18 \%$ & & $0 \%$ \\
\hline Overall agreement & $91 \%$ & & & & \\
\hline
\end{tabular}

believe CCDM offers an important evolution in the advancement of large area change detection with remote sensing. CCDM strives to balance the sometimes conflicting spectral trajectories and patterns of different land cover classes in an overall algorithm that remains effective at national scales. While the development of CCDM has provided significant gains in mapping efficiencies and accuracy improvement, we caution that some human interpretation and judgment is still necessary to finalize the land cover change products. Our goal has been to optimize the amount of human interpretation required to produce our products, not try to eliminate it.

\section{Conclusions}

For development of NLCD 2011, we designed, implemented, tested, and evaluated a new Comprehensive Change Detection Method (CCDM). The CCDM integrates spectral information from multi-date
Landsat images, information on land cover status, and prior knowledge about the trajectory of land cover trends to obtain a maximum potential spectral change map with the goal of minimizing omission error without introducing large commission error. The CCDM method has been tested covering a footprint of thirteen Landsat path/row that cover many ecoregions of the conterminous United States with a variety of natural and anthropogenic induced land cover change and disturbances.

Results from the two exemplar study areas (two Landsat path/rows) reported in this paper show $100 \%$ agreement for the no-change class, and $18 \%$ and $88 \%$ disagreement for change class for p22r39 and p33r33, respectively. Despite the fact that the maximum potential spectral change map is not the final land cover change product, we used the criteria of land cover change to assess the accuracy of this spectral change map to be consistent with the ultimate goal of detecting real land cover changes. The strength of the CCDM is that it is simple, easy to operate, robust, and capable of capturing different disturbances on a variety of landscapes.
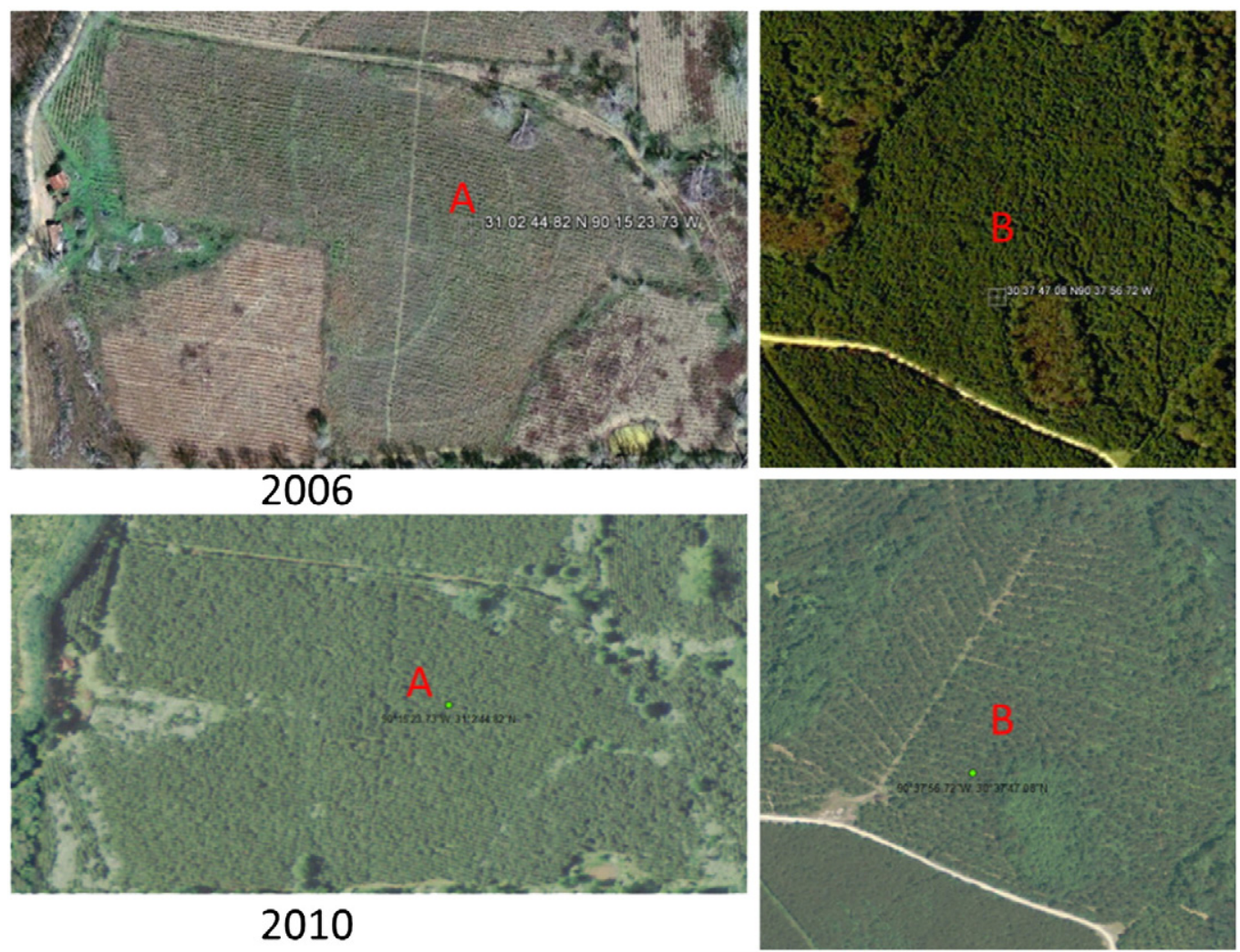

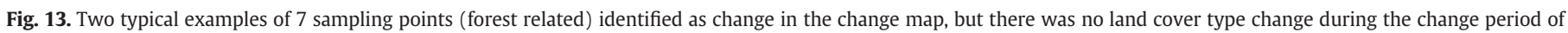
2006-2011. The top row aerial photos are from 2006 (obtained from Google Earth) and the bottom row photos are 2010 NAIP images. 
Table 2

Accuracy assessment results of 100 samples for p33r33.

\begin{tabular}{|c|c|c|c|c|c|}
\hline \multirow[t]{2}{*}{ NLCD2006 (class name/code) } & \multirow[t]{2}{*}{ Number of samples } & \multicolumn{2}{|c|}{ Change between 06 and 11} & \multicolumn{2}{|c|}{ No change between 06 and 11} \\
\hline & & Sample \# & Disagreement \# & Sample \# & Disagreement \# \\
\hline Barren land (31) & 1 & 0 & 0 & 1 & 0 \\
\hline Urban $(21,22,23,24)$ & 2 & 0 & 0 & 2 & 0 \\
\hline Forests $(41,42,43)$ & 19 & 8 & 6 & 11 & 0 \\
\hline Shrub/Scrub (52) & 12 & 7 & 5 & 5 & 0 \\
\hline Grassland/Herbaceous (71) & 46 & 16 & 14 & 30 & 0 \\
\hline Agriculture $(81,82)$ & 18 & 17 & 17 & 1 & 0 \\
\hline Woody wetlands (90) & 1 & 1 & 1 & 0 & 0 \\
\hline Emergent herbaceous wetlands (95) & 1 & 1 & 1 & 0 & 0 \\
\hline Sum & 100 & 50 & 44 & 50 & 0 \\
\hline Disagreement percentage & & & $88 \%$ & & $0 \%$ \\
\hline Overall agreement & $56 \%$ & & & & \\
\hline
\end{tabular}

Some weaknesses of the CCDM are that it detects change for only one time period (focus on land cover shifting disturbance) and can still have a certain amount of commission errors.

The core module of the CCDM method is MIICA, which was employed to produce NLCD 2006 change products (published online and freely available to download). With the additional Zone model and combination strategy, we believe that the NLCD 2011 products developed from CCDM will have higher quality and require much less workload with regard to manual editing and pre- and post-processing for a national implementation. In general, the MIICA and Zone models have great potential to be applied to other regional or global projects that use remote sensing data for monitoring and mapping land cover and land surface changes. Our NSD concept can be used to identify base-error in the historical land cover data sets and to detect changes of certain land cover types with a tight spectral signature range. Overall, the CCDM presents a sound change detection framework for national land cover updating and land cover change monitoring.

\section{Acknowledgments}

The authors thank Thomas Adamson for his great editing. We also thank Shengli Huang and Lei Ji for their insightful reviews and comments to the manuscript. Any use of trade, product, or firm names is for descriptive purposes only and does not imply endorsement by the U.S. Government.

\section{References}

Chander, G., Huang, C., Yang, L., Homer, C. G., \& Larson, C. (2009). Developing consistent Landsat data sets for large area applications-The MRLC 2001 Protocol. IEEE Geoscience and Remote Sensing Letters, 6, 777-781.

Cohen, W. B., Yang, Z., \& Kennedy, R. E. (2010). Detecting trends in forest disturbance and recovery using yearly Landsat time series: 2 . TimeSync - Tools for calibration and validation. Remote Sensing of Environment, 114, 2911-2924.

Foley, J. A., DeFries, R., Asner, G. P., Barford, C., Bonan, G., Carpenter, S. R., et al. (2005). Global consequences of land use. Science, 309, 570-574.

Fry, J., Xian, G., Jin, S., Dewitz, J., Homer, C., Yang, L., et al. (2011). Completion of the 2006 National Land Cover Database for the Conterminous United States. Photogrammetric Engineering and Remote Sensing, 77, 858-864.

Gong, J., Sui, H., Ma, G., \& Zhou, Q. (2008). A review of multi-temporal remote sensing data change detection algorithms. In J. Chen, J. Jiang, \& J. Van Genderen (Eds.), Proceedings of the 21st ISPRS Congress Beijing 2008, The International Archives of the Photogrammetry. Remote Sensing and Spatial Information Sciences, Beijing, China, 3-11 Jul, 37(B7). (pp. 757-762).

Green, K., Kempka, D., \& Lackey, L. (1994). Using remote sensing to detect and monitor land-cover and land-use change. Photogrammetric Engineering and Remote Sensing. $60,331-337$.

Hansen, M., Roy, D. P., Lindquist, E., Justice, C., \& Alstatt, A. (2008). A method for integrating MODIS and Landsat data for systematic monitoring of forest cover and change in Central Africa. Remote Sensing of Environment, 112(5), 2495-2513.

Healey, S. P., Cohen, W. B., Yang, Z., \& Krankina, O. N. (2005). Comparison of Tasseled-Cap-based Landsat data structures for use in forest disturbance detection. Remote Sensing of Environment, 97, 301-310.
Homer, C., Dewitz, J., Fry, J., Coan, M., Hossain, N., Larson, C., et al. (2007). Completion of the 2001 National Land Cover Database for the conterminous United States. Photogrammetric Engineering and Remote Sensing, 73, 337-341.

Homer, C., Huang, C., Yang, L., Wylie, B., \& Coan, M. (2004). Development of a $2001 \mathrm{Na}-$ tional Land Cover Database for the United States. Photogrammetric Engineering and Remote Sensing, 70, 829-840.

Huang, C., Goward, S. N., Masek, J. G., Thomas, N., Zhu, Z., \& Vogelmann, J. E. (2010). An automated approach for reconstructing recent forest disturbance history using dense Landsat time series stacks. Remote Sensing of Environment, 114, 183-198.

Huang, C., Song, K., Kim, S., Townshend, J., Davis, P., Masek, J., et al. (2008). Use of a dark object concept and support vector machines to automate forest cover change analysis. Remote Sensing of Environment, 112, 970-985.

Jensen, J. R., Rutchey, K., Koch, M. S., \& Narumalani, S. (1995). Inland wetland change detection in the everglades water conservation area: Using a time series of normalized remotely sensed data. Photogrammetric Engineering and Remote Sensing, 61, 199-209.

Jin, S., \& Sader, S. A. (2005). Comparison of time-series tasseled cap wetness and the normalized difference moisture index in detecting forest disturbances. Remote Sensing of Environment, 94, 364-372.

Kam, T. S. (1995). Integrating GIS and remote sensing techniques for urban land-cover and land-use analysis. Geocarto International, 10, 39-49.

Kennedy, R. E., Townsend, P. A., Gross, J. E., Cohen, W. B., Bolstad, P., Wang, Y. Q., et al. (2009). Remote sensing change detection tools for natural resource managers: Understanding concepts and tradeoffs in the design of landscape monitoring projects. Remote Sensing of Environment, 113, 1382-1396.

Kennedy, R. E., Yang, Z., \& Cohen, W. B. (2010). Detecting trends in forest disturbance and recovery using yearly Landsat time series: 1 . LandTrendr - Temporal segmentation algorithms. Remote Sensing of Environment, 114, 2897-2910.

Latifovic, R., \& Pouliot, D. (2005). Multitemporal land cover mapping for Canada: Methodology and products. Canadian Journal of Remote Sensing, 31(5), 347-363.

Loveland, T. R., Sohl, T. L., Stehman, S. V., Gallant, A. L., Sayler, K. L., \& Napton, D. F. (2002). A strategy for estimating the rates of recent United States land-cover changes. Photogrammetric Engineering and Remote Sensing, 68, 1091-1099.

Lu, D., Mausel, P., Brondizio, E., \& Moran, E. (2004). Change detection techniques. International Journal of Remote Sensing, 25, 2365-2407.

Lunetta, R. S., Knight, J. F., Ediriwickrema, J., Lyon, J. G., \& Worthy, L. D. (2006). Land cover change detection using multi-temporal MODIS NDVI data. Remote Sensing of Environment, 105, 142-154.

Matthews, H. D., Weaver, A. J., Meissner, K. J., Gillett, N. P., \& Eby, M. (2004). Natural and anthropogenic climate change: Incorporating historical land cover change, vegetation dynamics and the global carbon cycle. Climate Dynamics, 22, 461-479.

Pouliot, D., Latifovic, R., Fernandes, R., \& Olthof, I. (2009). Evaluation of annual forest disturbance monitoring using a static decision tree approach and $250 \mathrm{~m}$ MODIS data. Remote Sensing of Environment, 113, 1749-1759.

Ridd, M. K., \& Liu, J. (1998). A comparison of four algorithms for change detection in an urban environment. Remote Sensing of Environment, 63, 95-100.

Sader, S. A., \& Winne, J. C. (1992). RGB-NDVI color composites for visualizing forest change dynamics. International Journal of Remote Sensing, 13, 3055-3067.

Shafer, G., \& Logan, R. (1987). Implementing Dempster's rule of hierarchical evidence. Artificial Intelligence, 33, 271-298.

Singh, A. (1989). Digital change detection techniques using remotely sensed data International Journal of Remote Sensing, 10, 989-1003.

Sohl, T. (1999). Change analysis in the United Arab Emirates: An investigation of techniques. Photogrammetric Engineering and Remote Sensing, 65, 475-484.

Srinivasan, A., \& Richards, J. A. (1990). Knowledge-based techniques for multi-source classification. International Journal of Remote Sensing, 11, 505-525.

Turner, B. L., II, Lambin, E., \& Reenberg, A. (2007). The emergence of land change science for global environmental change and sustainability. Proceedings of the National Academy of Sciences of the United States of America, 104, 20666-20671.

Vogelmann, J. E., Howard, S. M., Yang, L., Larson, C. R., Wylie, B. K., \& Van Driel, J. N. (2001). Completion of the 1990s National Land Cover Data Set for the 
conterminous United States. Photogrammetric Engineering and Remote Sensing, $67,650-662$.

Xian, G., \& Homer, C. (2009). Updating the 2001 National Land Cover Database impervious surface products to 2006 using Landsat imagery change detection methods. Remote Sensing of Environment, 114, 1676-1686.

Yang, X., \& Lo, C. (2002). Using satellite imagery to detect land use land cover changes in Atlanta, Georgia metropolitan area. International Journal of Remote Sensing, 23, 1775-1798.
Yang, L., Xian, G., Klaver, J., \& Deal, B. (2003). Urban land-cover change detection through sub-pixel impervious surface mapping using remotely sensed data. Photogrammetric Engineering and Remote Sensing, 69, 1003-1010.

Zhan, X., DeFries, R., Townshend, J. R. G., DiMiceli, C., Hansen, M., Huang, C., et al. (2000). The $250 \mathrm{~m}$ global land cover change product from the Moderate Resolution Imaging Spectroradiometer of NASA's Earth Observing System. International Journal of Remote Sensing, 21, 1433-1460. 